
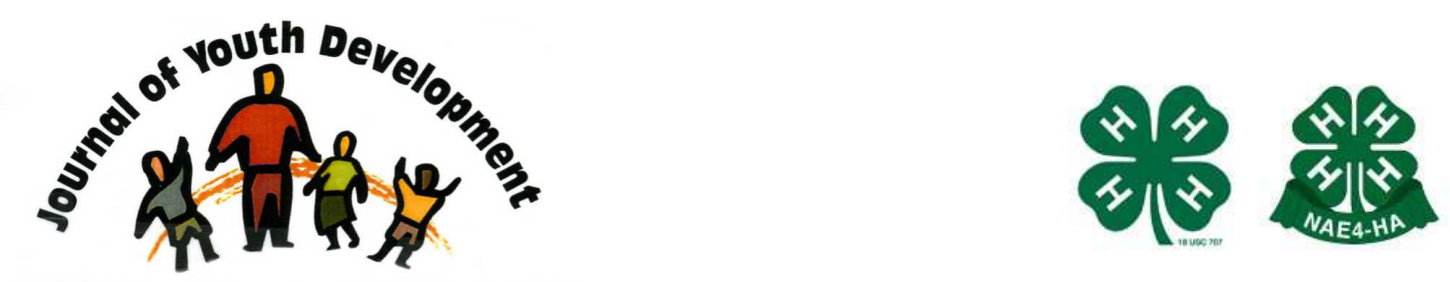

Bridging Research \& Practice

\title{
Covering our Bases: \\ A Military 4-H Youth Development Program
}

\author{
Joanne Roueche \\ Utah State University Extension \\ joanner@ext.usu.edu
}

Debra A. Jones

Utah State University Extension

deb.jones@usu.edu 


\title{
JOURNAL OF YOUTH DEVELOPMENT \\ bridging research and practice

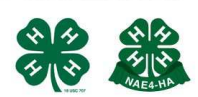

Volume 3, Number 2, Fall 2008

Article 080302PA004

\section{Covering our Bases: A Military 4-H Youth Development Program}

Joanne Roueche and Debra A. Jones

Utah State University Extension

\begin{abstract}
Land-grant universities, through the 4-H program, have offered support and partnership to the military since World War I. More recently, the U. S. Army, Air Force, and 4-H have partnered to provide military installation youth programs involving over 7,000 youth in $4-\mathrm{H}$ clubs in the United States and abroad. Military youth and families, not affiliated with Base or Post installations, were extended similar support as an aftermath of September 11, 2001. All youth involved through military outreach are enrolled as 4- $\mathrm{H}$ members through their respective counties integrating them into local, state, regional, and national 4-H activities and events. Authors share their experience developing relationships with their Air Force partner in implementing positive youth development programs, and explain how these actions resulted in successful funding for increased outreach.
\end{abstract}

\section{Introduction}

Partnership between Cooperative Extension and the U.S. military dates back to at least World War I, with Congress appropriating funding for Extension to increase food production from America's farmers. The war brought about labor shortages, and 4-H club work in rural areas became a way to increase production. At the beginning of World War I, 4-H club membership totaled 169,000 . By 1918, the year after the United States entered the war, membership had reached 500,000 (Reck, 1951).

World War II brought new and different challenges to 4-H and to our nation. With food in short supply and much of the male population at war, the Extension Service began a 4-H campaign to "Feed a Fighter." 4-H youth preserved enough food to care for one million fighting men for three years (Reck, 1951). Midway through the war, the Extension Service, in cooperation with the Maritime Commission, worked with $4-\mathrm{H}$ youth to sell war bonds. The goal of the bond sale 
was to raise $\$ 2,000,000$ to build a Liberty ship - which would be named after a $4-\mathrm{H}$ or Extension pioneer. Forty ships went to sea as a result of this effort. On a smaller scale, one 4-H club collected five tons of milkweed floss to help with the construction of 1,100 life vests.

As the history of our nation evolves, the partnership between Extension and the military endures and strengthens to meet the ever-changing needs of society. In 1995, a formal agreement was formed among National 4-H Headquarters, the U.S. Army Child and Youth Services, and the U.S. Air Force Family Members Program to provide 4-H on military installations around the world. In the aftermath of September 11, 2001, the initiative now provides similar support to military youth of National Guard and Reserve families who are dispersed in rural, urban and suburban communities across the nation. Nationally, the military 4-H partnership has established 450 4-H clubs, involving 12,000 youth and 900 Army staff at 95 installations worldwide (Military 4-H, 2006).

While the authors enjoy positive relationships with military partners in Army, Air Force, National Guard and Reserve, this article focuses specifically on the partnership between 4-H and Air Force. Air Force Base Youth Center staff in this western state estimate that over $50 \%$ of youth enrolled at the Center have at least one parent currently deployed. Issues of deployment and family separation are dominant aspects of military service, with the National Council on Family Relations (2004) recommending an increase in prevention and outreach efforts. 4- $\mathrm{H}$ and other youth serving agencies can serve an integral role in connecting deployed families with community support systems and resources.

\section{Highlights of the 4-H/Air Force Program}

The initial seed planted in the present 4-H/Air Force partnership was a result of one of the author's personal experiences of having a son deployed to Iraq. Experiencing the stress of deployment and how it affects families, she began seeking opportunities to work with military youth. The first outreach effort was an overnight outdoor camping experience conducted at the Base Youth Center. The partnership continued to develop through various activities such as 4-H skill-a-thons, service projects, and community based activities. Through this growing partnership, the request was made by the Base to help them supplement temporary summer staff with 4-H interns. The internship proved to be a "win-win" collaboration. Four 4-H interns were hired for 12 weeks in the summer to help with youth activities and to conduct weekly 4-H clubs at the Military Base. Through this collaboration over 150 youth have become 4-H members and are encouraged to participate in a variety of 4- $\mathrm{H}$ projects, activities, and events. The 4-H summer intern program is now entering its fourth year - and promises to continue.

Afterschool Club. As a result of the internship program, a weekly afterschool 4-H club was initiated on Base and continues to thrive. Youth participate in many projects, with the rocketry project one of the recent favorites. Youth not only built and tested their own rockets, but entered them in the county fair, and provided a rocket launching demonstration for fair goers. A special exhibit area is provided within the 4-H area of the county fair for military youth to display their projects. County fair exhibits provide not only recognition but visibility and a positive impact on relations between the Base and the community. A key aspect of the 4-H clubs is collaboration with Boys and Girls Clubs, also offered on Base. Together, we provide service projects involving military youth in a variety of experiences connecting them with the community. Base Youth Center staff are also involved beyond the club level, by serving on the County Fair Board, Extension Advisory Councils, and as youth mentors. These experiences provide a bridge between the Base and the community. 
Operation Purple. 4-H was invited to provide five camp counselors for a camp titled Operation Purple Camp as a result of our involvement in the summer and afterschool programs. Camp is available to youth of personnel from all branches of the U.S. Armed Forces at no cost to campers, courtesy of grants from the National Military Families Association and Sears, Roebuck and Company. The week long camps focus on helping youth deal with deployment-related issues in a safe, fun environment where they can process their feelings with others in similar situations. Over 10,000 military youth have participated in Operation Purple Camp since its inception in 2004. States interested in hosting a camp are encouraged to review current proposal guidelines at the National Military Family Association website, www.nmfa.org.

The impact of Purple Camp was felt not only by youth participants but a 4-H intern as well. One of the interns had experienced "near deployment" of a parent, and was able to relate very well with the campers, while also helping her process feelings which she had been suppressing. Leonhard and Ferrari (2006) suggest the greatest benefit of Purple Camp is for campers to meet other youth who are experiencing similar emotions and challenges of deployment, and to realize they are not alone.

FitFactor. A new component of the Military 4- $\mathrm{H}$ afterschool program is the inclusion of 4- $\mathrm{H}$ FitFactor, with 108 youth currently enrolled in weekly experiential learning activities pertaining to healthy and fit lifestyles. FitFactor is an online AF program designed to help youth track physical fitness, nutrition, and healthy lifestyle activities by earning participation points. These points help youth reach different levels of achievement and qualify for awards. 4-H has partnered with certified fitness trainers, dance instructors and professional athletes to provide research based activities, nutrition education, and healthy lifestyle activities. Weekly 4-H activities are conducted to introduce youth to various types of physical and recreational activities. Community leaders and volunteers provide these activities in a safe and inclusive learning environment. Some of the highlights include yoga, kickboxing, tumbling, Polynesian dancing, line dancing, hip hop, Pilates, and a youth boot camp.

Following the physical activities, youth are involved in short nutrition-based education activities. These activities help them learn about making wise food choices by learning about the Food Pyramid and making fun nutritious snacks. Youth have not only been able to gain a more fit lifestyle but they have also had the experience of entering their points into the national FitFactor database to track their individual and group progress. The community has been involved not only in helping with fitness instruction and donating snack items, but through media promotion and recognition.

\section{Impacts}

While it is difficult to determine the full impact of the military 4-H program, cumulative evidence indicates positive developments in youth as well as with partnering agencies. Impacts are evident in grants awarded, program recognition, media coverage, and community participation and support. Through support of our military partners over the last few years, USU Extension 4-H has increased outreach to military families from 3 clubs and 18 youth, to 16 clubs and 428 youth, with 124 youth in Army families; 190 Air Force; and 114 National Guard (Jones et al., 2006). Over the course of three years, the AF Base summer intern program has involved 17 young adult interns and reached almost 600 youth. Grant funding has provided over $\$ 160,000$ for implementation of military programs over the last four years, with invitations to become involved in additional national and locally based funding streams. 
Beyond the numbers, some of the most important impacts have been noted in building relationships and credibility with our military and community partners. Media coverage of $4-\mathrm{H}$ activities on Base and with the County Fair has delivered the message of positive youth development outreach to households along one of the most populated areas of this western state. Based on surveys and anecdotal evidence, youth and teen leaders alike feel that 4-H affords them the opportunity to be part of an expanded family across the nation and the world.

\section{Summary and Implications for Extension}

USU Extension's military 4-H program has experienced some of the challenges noted in a study conducted by Ferrari and Lauxman (2005). They suggested that major challenges in developing and sustaining military $4-\mathrm{H}$ partnerships are making and maintaining contacts due to a high rate of military staff turnover, time constraints, learning and navigating military culture, and defining clear expectations of all partners. Utah has also experienced what the study considers to be some of the greatest benefits of the partnerships - a sense of making a difference in the lives of youth and within the community, providing meaningful opportunities to youth and families not previously being served by Extension, increased visibility for Extension, and funding to implement effective programs.

Ferrari (2005) voices thoughts that are shared by many within the military 4-H network. The need to address family instability has become the norm as more and more families are affected by multiple deployments. Extension, through the support of USDA, Army and Air Force, is strengthening its role as convener and facilitator of community collaborations to make programs more accessible to those who need them. Families and communities benefit as Extension and 4- $\mathrm{H}$ make a difference in the lives of youth. Perhaps one of the greatest benefits of military 4-H programming is that youth are able to take the 4- $\mathrm{H}$ experience wherever their families happen to be stationed on military installations around the world.

\section{References}

Ferrari, T., \& Lauxman, L. (2005). What we have learned from joining forces with the military: Challenges, lessons learned, and creative solutions. Presentation at Children, Youth and Families at Risk (CYFAR) Conference, May 26, Boston, MA.

Ferrari, T. (2005). Extension's response to an un-natural disaster: Enlisting your support for military youth and families. Journal of Extension, 43(4), available on-line at http://www.joe.org/joe/2005august/comm1.shtml

Jones, D., Smith, J., Roueche, J., Christian, J., Nielsen, B., \& Thornton, L. (2006). Strengthening families through 4- $\mathrm{H}$ military partnerships. Presentation at Children, Youth and Families at Risk (CYFAR) Conference, May 17, Atlanta, GA.

Leonhard, D., \& Ferrari, T. (2006). Youth's coping strategies used during a parent's military deployment and benefits from attending operation purple camp. Presentation at Children, Youth and Families at Risk (CYFAR) Conference, May 16, Atlanta, GA.

Military 4-H. (2006). Extension/4-H support for military youth and family programs. Retrieved December 27, 2007 at www.csrees.usda.gov/nea/family/cyfar/military.html. 
National Council on Family Relations. 2004, April. Building strong communities for military families. NCFR Policy Brief. Strengthening families: Bridging research, practice, and policy. Minneapolis, MN.

Reck, F. (1951). The 4-H Story: A History of 4-H Work. Ames, Iowa: Iowa State College Press.

(c) Copyright of Journal of Youth Development $~$ Bridging Research and Practice. Content may not be copied or emailed to multiple sites or posted to a listserv without copyright holder's express written permission. Contact Editor at: patricia.dawson@oregonstate.edu for details. However, users may print, download or email articles for individual use.

ISSN 2325-4009 (Print); ISSN 2325-4017 (Online) 